\title{
JOINT SELECTION FOR BOTH EXTREMES OF MEAN PERFORMANCE AND OF SENSITIVITY TO A MACRO- ENVIRONMENTAL VARIABLE
}

\author{
I. FAMILY SELECTION
}

\author{
R. J. BRUMPTON, HILARIE BOUGHEY and J. L. JINKS \\ Department of Genetics, University of Birmingham, Birmingham B/5 2TT
}

Received 12.x.76

\begin{abstract}
SUMMARY
In spite of the frequency with which mean performance and sensitivity to macro-environmental variables are found to be highly correlated, there is a growing body of evidence that they are, at least in part under independent genetical control. From a cross between two pure breeding lines which segregate for both of these aspects of the phenotype it should, therefore, be possible to select recombinants which display all four possible combinations of high and low performance with high and low sensitivity. This prediction has been tested by two cycles of selection initiated in the $F_{3}$ of a cross between varieties 2 and 12 of Nicotiana rustica for the mean performance and environmental sensitivity of two characters, flowering time and final height. Selection was on a family basis, date of sowing being the macro-environmental variable. Qualitatively, three of the four combinations for flowering time and three of the four for final height met the selection criteria by the $\mathrm{F}_{5}$. Quantitatively, however, all selections fell short of what could have been achieved if all the genetical variation in performance and sensitivity had been independently available for selection. The realised heritability for sensitivity was only half that for performance. The expectation that selection among inbreds produced from the same cross by single seed descent would have been more successful is being tested.
\end{abstract}

\section{INTRODUGTION}

MEAN performance and sensitivity to a macro-environmental variable have been shown to be, at least in part, under independent genetical control in a number of crosses between pure breeding varieties of Nicotiana rustica (Perkins and Jinks, 1968, 1971, 1973). The correlations between performance and environmental sensitivity that are so often found in this material should, therefore, be breakable following cross breeding and segregation and it should be possible to select from among the segregants a range of combinations of these two aspects of the phenotype.

Using families derived from a cross between varieties 2 and 12 of the Birmingham Nicotiana rustica collection, a selection experiment was initiated in an attempt to break this correlation for two characters, flowering time (FT) and final height $(\mathrm{FH})$. Simultaneous selection for all four combinations of high $(\mathrm{H})$ and low (L) mean performance and high (h) and low (l) environmental sensitivity was carried out for each character, the environmental variable being the difference between early and late sowing (Perkins and Jinks, 1971, 1973). 


\section{Material And method}

The selection programme was initiated in 1969 from $18 F_{3}$ families derived by selfing 18 randomly chosen $F_{2}$ plants from the cross $\mathrm{V} 2 \times \mathrm{V} 12$. Ten randomly chosen plants of each $F_{3}$ family were grown in each of two replicate blocks in each of two sowings made 4 weeks apart. All plants within a block were individually randomised.

For each of the characters, FT and FH, four families were selected, one for each of the four combinations of high and low means performance and high and low environmental sensitivity ( $\mathrm{Hh}, \mathrm{Hl}, \mathrm{Lh}$ and $\mathrm{Ll}$ ). Mean performance was measured as the family mean summed over the two sowings and environmental sensitivity as the family mean differenced over the two sowings. To give equal weight to performance and sensitivity in making the selections both measures were standardised by dividing all sums and all differences by their respective standard deviations derived from the sums and differences of all $18 \mathrm{~F}_{3}$ families.

Ten randomly chosen siblings of each of the selected $F_{3}$ families were raised during the winter of $1969-70$ and selfed to give $10 \mathrm{~F}_{4}$ families or sublines. All $\mathrm{F}_{4}$ families were assessed during the following season using exactly the same experimental design and procedures as for the $F_{3}$ families. From the $10 \mathrm{~F}_{4}$ families available for each selection the one which came closest to the selection criterion was chosen to produce an $\mathrm{F}_{5}$. For example, for the $\mathrm{Hh}$ selection for final height there were 10 families each represented by 10 individually randomised plants in each of two replicate blocks in each of the two sowings. From these 10 families one was selected on the basis of the standardised sum and difference over sowings which came closest to combining a high sum and a high difference. Ten randomly chosen siblings of each of the selected $F_{4}$ families were raised during the winter of 1970-71 and selfed to give $10 \mathrm{~F}_{5}$ families or sub-lines. These $F_{5}$ families were assessed during the following season using the same experimental design and procedures as for the earlier generation.

In each of the three seasons, 1969, 1970 and 1971, a number of controls were grown along with the families under test. These included the parents, $\mathrm{V} 2$ and V12, reciprocal $\mathrm{F}_{\mathrm{1}} \mathrm{s}$ and control lines (C) which were chosen and perpetuated in each generation in a similar manner to the selection lines. For each character (FT and FH) four lines were chosen from among the $18 \mathrm{~F}_{3}$ families whose standardised sums and differences over sowings were closest to the mean sum and difference over all families. In the following season $10 \mathrm{~F}_{4}$ families were grown for each of the four control lines and similarly $10 \mathrm{~F}_{5}$ families were grown for each of two control lines in 1971 . The compositions of the experiments grown in the three seasons are summarised in table 1.

During the course of these experiments an unexpected difficulty arose in applying the selection criterion for environmental sensitivity. In preliminary experiments up to and including the assessment of the $F_{3}$ families in 1969 the differences between the two sowings $\left(\mathrm{S}_{1}-\mathrm{S}_{2}\right)$ were with rare exceptions positive for FT and negative for FH. An environmentally sensitive (h) family, therefore, had a large positive difference for FT and a large negative difference for $\mathrm{FH}$ while an environmentally insensitive family (1) had a smaller or no difference for FT or FH. This situation more or less persisted for FT throughout these experiments. For FH, however, families with 
positive and negative differences of comparable magnitude were almost equally frequent in both the selection and control sub-lines of the $F_{4}$ and $F_{5}$ generations. Since this change in reaction to sowings affected selections and controls alike its cause must have been changes in the environments rather than changes in the genotypes brought about by selection. As a result of this change in the phenotypic effect of the difference in time of

TABle 1

Composition of the selection experiment for each character

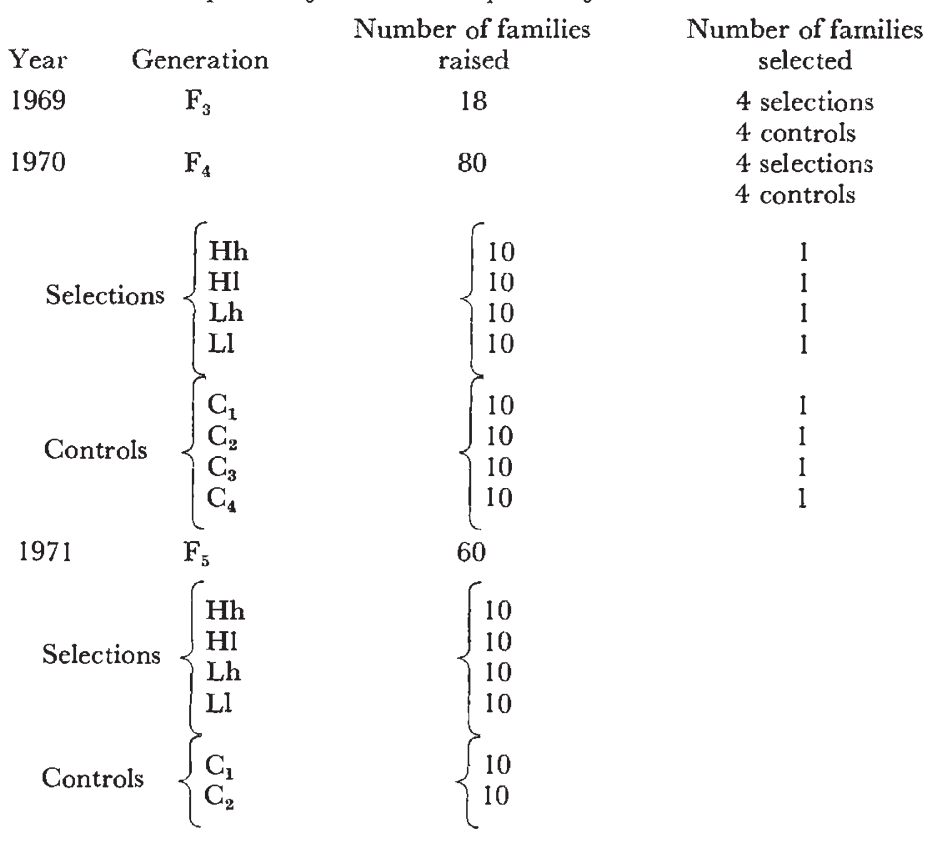

sowing, low or zero scores were no longer the lower extreme of the distribution of differences but the mean of the distribution. $F_{4}$ and $F_{5}$ families with low or zero scores could no longer, therefore, be regarded as meeting the criterion of low environmental sensitivity as initially defined since there had been an essentially linear scalar change in the distribution of differences between the $F_{3}$ and the $F_{4}$ and $F_{5}$ generations. The positive and negative extremes of this distribution were, therefore, accepted as satisfying the selection criterion for the $\mathrm{F}_{4}$ selections for $\mathrm{FH}$.

\section{Results}

(i) Measures of mean performance and environmental sensitivity

For each $F_{3}, F_{4}$ and $F_{5}$ family raised (table 1 ) a one way analysis of variance was carried out in order to partition the variation in $\mathrm{FT}$ and $\mathrm{FH}$ into within $\left(\sigma_{w}^{2}\right)$ and between $\left(\sigma_{b}^{2}\right)$ environmental (sowings) components. The estimate of $\sigma_{b}$ was used in all subsequent analyses as the measure of the macro-environmental sensitivity of a family for the character and the family mean averaged over environments (sowings) as the measure of its 
mean performance. To minimise the effects of the seasonal differences, mean performance and environmental sensitivity for the families or sub-lines of the selection lines are expressed as deviations from the corresponding mean performance and environmental sensitivity of the controls averaged over all the control families grown in the same season.

\section{(ii) Selection pressure}

The selection pressures $(\mathrm{S})$ applied to the $\mathrm{F}_{3}$ and $\mathrm{F}_{4}$ generations in choosing the parents of the four selections for FT and FH are given in table 2. These were calculated in the usual way (Falconer, 1960) as the

\section{TABLE 2}

The selection pressures applied and the response obtained for the performance and sensitivity of the four selection lines in each generation

\begin{tabular}{|c|c|c|c|c|c|c|c|}
\hline \multirow[b]{2}{*}{$\begin{array}{l}\text { Generation } \\
\text { Flowering time }\end{array}$} & \multirow{2}{*}{$\begin{array}{l}\text { Selection } \\
\text { line }\end{array}$} & \multicolumn{3}{|c|}{ Performance } & \multicolumn{3}{|c|}{ Sensitivity } \\
\hline & & $\mathrm{S}_{\max }$ & $\mathrm{S}$ & $\mathrm{R}$ & $\mathrm{S}_{\max }$ & $S$ & $\mathrm{R}$ \\
\hline $\mathrm{F}_{3}$ & $\begin{array}{l}\mathrm{Hh} \\
\mathrm{Hl} \\
\mathrm{Lh} \\
\mathrm{Ll}\end{array}$ & $\begin{array}{r}23.03 \\
23.03 \\
-6.76 \\
-6.76\end{array}$ & $\begin{array}{r}4 \cdot 45 \\
23.03 \\
-5 \cdot 00 \\
-3 \cdot 41\end{array}$ & $\begin{array}{c}- \\
- \\
-\end{array}$ & $\begin{array}{r}6 \cdot 03 \\
-8.22 \\
6 \cdot 03 \\
-8.22\end{array}$ & $\begin{array}{r}1.37 \\
6.03 \\
3.53 \\
-5.55\end{array}$ & $\begin{array}{l}- \\
\text { - }\end{array}$ \\
\hline$F_{4}$ & $\begin{array}{l}\mathrm{Hh} \\
\mathrm{Hl} \\
\mathrm{Lh} \\
\mathrm{Ll}\end{array}$ & $\begin{array}{r}5 \cdot 70 \\
6.02 \\
-6 \cdot 28 \\
-2.93\end{array}$ & $\begin{array}{r}-2.02 \\
6.02 \\
-4.08 \\
-2.23\end{array}$ & $\begin{array}{r}6.44 \\
19.13 \\
0.80 \\
-6.08\end{array}$ & $\begin{array}{r}4.90 \\
-3.95 \\
1.56 \\
-0.92\end{array}$ & $\begin{array}{r}4.90 \\
-0.10 \\
0.37 \\
-0.92\end{array}$ & $\begin{array}{r}0.61 \\
-3.06 \\
-0.21 \\
-0.80\end{array}$ \\
\hline$F_{5}$ & $\begin{array}{l}\mathrm{Hh} \\
\mathrm{Hl} \\
\mathrm{Lh} \\
\mathrm{Ll}\end{array}$ & $\begin{array}{l}- \\
- \\
-\end{array}$ & $\begin{array}{l}- \\
- \\
-\end{array}$ & $\begin{array}{r}7 \cdot 15 \\
21 \cdot 15 \\
-0 \cdot 19 \\
-2 \cdot 89\end{array}$ & $\begin{array}{l}- \\
- \\
-\end{array}$ & $\begin{array}{l}- \\
- \\
-\end{array}$ & $\begin{array}{r}2.27 \\
-0.92 \\
-0.96 \\
-1.91\end{array}$ \\
\hline \multicolumn{8}{|l|}{ Final height } \\
\hline $\mathrm{F}_{3}$ & $\begin{array}{l}\mathrm{Hh} \\
\mathrm{H} 1 \\
\mathrm{Lh} \\
\mathrm{Ll}\end{array}$ & $\begin{array}{r}28 \cdot 44 \\
28 \cdot 44 \\
-46 \cdot 47 \\
-46 \cdot 47\end{array}$ & $\begin{array}{r}26 \cdot 21 \\
28 \cdot 44 \\
-13 \cdot 21 \\
-46 \cdot 47\end{array}$ & $\begin{array}{l}- \\
-\end{array}$ & $\begin{array}{r}6.81 \\
-11.84 \\
6.81 \\
-11.84\end{array}$ & $\begin{array}{r}4 \cdot 12 \\
-1 \cdot 63 \\
5 \cdot 15 \\
-7 \cdot 44\end{array}$ & $\begin{array}{l}- \\
-\end{array}$ \\
\hline $\mathrm{F}_{4}$ & $\begin{array}{l}\mathrm{Hh} \\
\mathrm{Hl} \\
\mathrm{Hh} \\
\mathrm{Ll}\end{array}$ & $\begin{array}{r}19 \cdot 49 \\
14 \cdot 64 \\
-14 \cdot 61 \\
-14 \cdot 96\end{array}$ & $\begin{array}{r}19 \cdot 49 \\
10 \cdot 26 \\
7 \cdot 44 \\
5 \cdot 10\end{array}$ & $\begin{array}{r}18.57 \\
25 \cdot 25 \\
-19 \cdot 60 \\
-38 \cdot 74\end{array}$ & $\begin{array}{r}5 \cdot 27 \\
-4 \cdot 09 \\
5 \cdot 48 \\
-9 \cdot 13\end{array}$ & $\begin{array}{l}2 \cdot 82 \\
2 \cdot 56 \\
5 \cdot 48 \\
4 \cdot 80\end{array}$ & $\begin{array}{r}4 \cdot 46 \\
0.38 \\
-0 \cdot 10 \\
5 \cdot 48\end{array}$ \\
\hline $\mathrm{F}_{5}$ & $\begin{array}{l}\mathrm{Hh} \\
\mathrm{Hl} \\
\mathrm{Lh} \\
\mathrm{Ll}\end{array}$ & $\begin{array}{l}= \\
-\end{array}$ & $\begin{array}{l}- \\
-\end{array}$ & $\begin{array}{r}43 \cdot 39 \\
30 \cdot 84 \\
-10 \cdot 32 \\
-26 \cdot 32\end{array}$ & $\begin{array}{l}- \\
- \\
-\end{array}$ & $\bar{z}$ & $\begin{array}{r}11.47 \\
1.92 \\
0.70 \\
-1.18\end{array}$ \\
\hline
\end{tabular}

deviation of the mean of the selected family from the mean of all families available for selection. These are all the 18 families of the $F_{3}$ and the 10 families of each selection line in the $F_{4}$. The cumulative selection pressure applied to obtain each $F_{5}$ selection is, of course, the sum of the appropriate $\mathrm{F}_{3}$ and $\mathrm{F}_{4}$ selection pressures (table 3 ). Because we are selecting for mean performance and environmental sensitivity simultaneously we are unable to apply the selection pressure that would have been possible if we had been 
Table 3

Cumulative selection pressure and response (up to the $F_{5}$ generation) of the four selection lines for mean performance and sensitivity and the orthogonal comparisons among them

\begin{tabular}{|c|c|c|c|c|c|}
\hline $\begin{array}{l}\text { Selection line } \\
\text { Flowering time }\end{array}$ & Character & $S_{\max }$ & $\mathrm{S}$ & $\mathbf{R}$ & $\mathrm{R} / \mathrm{S}$ \\
\hline \multirow[t]{2}{*}{$\mathrm{Hh}$} & Performance $(\mathrm{H})$ & $28 \cdot 73$ & $2 \cdot 43$ & $7 \cdot 15$ & - \\
\hline & Sensitivity (h) & $10 \cdot 92$ & $6 \cdot 26$ & $2 \cdot 27$ & \\
\hline \multirow[t]{2}{*}{$\mathrm{Hl}$} & Performance $(\mathrm{H})$ & $29 \cdot 05$ & $29 \cdot 05$ & $21 \cdot 15$ & - \\
\hline & Sensitivity (I) & $-12 \cdot 17$ & $5 \cdot 93$ & -0.92 & - \\
\hline \multirow[t]{2}{*}{$\operatorname{Lh}$} & Performance (L) & -13.04 & -9.07 & $-0 \cdot 19$ & - \\
\hline & Sensitivity (h) & $7 \cdot 58$ & $3 \cdot 89$ & -0.96 & $\ldots$ \\
\hline \multirow[t]{2}{*}{$\mathrm{Ll}$} & Performance (L) & $-9 \cdot 69$ & $-5 \cdot 63$ & $-2 \cdot 89$ & - \\
\hline & Sensitivity (l) & $-9 \cdot 14$ & $-6 \cdot 47$ & $-1 \cdot 91$ & \\
\hline \multicolumn{6}{|l|}{ Performance } \\
\hline & $20 \cdot 13$ & $11 \cdot 55$ & $7 \cdot 85$ & $0 \cdot 68$ \\
\hline \multicolumn{2}{|l|}{ h $v .1$} & -0.92 & $-7 \cdot 51$ & $-2 \cdot 82$ & $0 \cdot 38$ \\
\hline \multicolumn{2}{|l|}{ Interaction } & $0 \cdot 76$ & $-5 \cdot 80$ & $-4 \cdot 17$ & $0 \cdot 72$ \\
\hline \multicolumn{6}{|l|}{ Sensitivity } \\
\hline \multicolumn{2}{|l|}{ h v. 1} & $9 \cdot 95$ & $2 \cdot 67$ & $1 \cdot 04$ & $0 \cdot 39$ \\
\hline \multicolumn{2}{|l|}{$\mathrm{H} v . \mathrm{L}$} & $0 \cdot 08$ & $3 \cdot 69$ & 1.05 & $0 \cdot 29$ \\
\hline \multicolumn{2}{|l|}{ Interaction } & $1 \cdot 59$ & $-2 \cdot 50$ & $0 \cdot 56$ & - \\
\hline \multicolumn{6}{|l|}{ Final height } \\
\hline \multirow[t]{2}{*}{$\mathrm{Hh}$} & Performance $(\mathrm{H})$ & $47 \cdot 93$ & $45 \cdot 70$ & $43 \cdot 39$ & $\longrightarrow$ \\
\hline & Sensitivity $(\mathrm{h})$ & $12 \cdot 08$ & 6.94 & $11 \cdot 47$ & - \\
\hline \multirow[t]{2}{*}{$\mathrm{Hl}$} & Performance $(\mathrm{H})$ & 43.09 & $38 \cdot 70$ & $30 \cdot 84$ & 一 \\
\hline & Sensitivity (I) & -15.93 & $-4 \cdot 19$ & 1.92 & - \\
\hline \multirow[t]{2}{*}{ Lh } & Performance (L) & $-61 \cdot 08$ & $-5 \cdot 78$ & $-10 \cdot 32$ & - \\
\hline & Sensitivity (h) & $12 \cdot 28$ & $10 \cdot 63$ & $0 \cdot 70$ & 一 \\
\hline \multirow[t]{2}{*}{$\mathrm{LI}$} & Performance (L) & $-61 \cdot 42$ & $-41 \cdot 37$ & $-26 \cdot 32$ & 一 \\
\hline & Sensitivity (I) & -20.97 & $-2 \cdot 64$ & $-1 \cdot 18$ & \\
\hline \multicolumn{6}{|l|}{ Performance } \\
\hline \multicolumn{2}{|l|}{$\mathrm{H} v . \mathrm{L}$} & $53 \cdot 38$ & $32 \cdot 89$ & $27 \cdot 72$ & $0 \cdot 84$ \\
\hline \multicolumn{2}{|l|}{ h $v .1$} & $1 \cdot 30$ & $10 \cdot 65$ & $7 \cdot 14$ & $0 \cdot 67$ \\
\hline \multicolumn{2}{|l|}{ Interaction } & $1 \cdot 13$ & $-7 \cdot 15$ & -0.86 & $0 \cdot 12$ \\
\hline \multicolumn{6}{|l|}{ Sensitivity } \\
\hline \multicolumn{2}{|l|}{ h $v .1$} & $5 \cdot 32$ & $6 \cdot 10$ & $2 \cdot 86$ & $0 \cdot 47$ \\
\hline \multicolumn{2}{|l|}{$\mathrm{H} v . \mathrm{L}$} & $1 \cdot 21$ & $-1 \cdot 31$ & $3 \cdot 47$ & - \\
\hline \multicolumn{2}{|l|}{ Interaction } & $1 \cdot 31$ & -0.53 & $1 \cdot 92$ & \\
\hline
\end{tabular}

selecting for each character independently. The selection pressure we could have applied in the latter circumstances $\left(S_{\max }\right)$ are listed in table 2.

\section{(iii) Response to selection}

The response to selection $(R)$ in the $F_{4}$ and $F_{5}$ generations for the four selections for FT and FH are also given in table 2. These were calculated, as already described, as deviations of the overall mean of the 10 families of each selection line from the overall mean of all the families of the controls grown in the same season.

\section{(iv) Analysis and interpretation}

The cumulative selection pressure that could have been applied if we had selected for performance and sensitivity independently $\left(\mathrm{S}_{\max }\right)$ and the 
cumulative selection pressure actually applied over the $\mathrm{F}_{3}$ and $\mathrm{F}_{4}$ generations are listed in table 3 for the four selections for each character. Also listed are the corresponding cumulative responses over the $F_{4}$ and $F_{5}$ generations. Since all entries are deviations from the controls grown in the same season, a positive value implies a performance or sensitivity that is higher than the controls and a negative value a performance or sensitivity that is lower than the controls. Both for FT and $\mathrm{FH}$ the $\mathrm{S}_{\max }$ column shows that there was no shortage of variation for either mean performance or sensitivity had we selected for high and low means and high and low sensitivities independently. There is some asymmetry in the available variation in favour of late flowering, small final height and below average sensitivity for final height. This asymmetry is small, however, compared with the truncation of the variation available for selection when we select for the best combination of performance and sensitivity simultaneously. Thus the entries in the $\mathrm{S}$ column of table 3 are in general much smaller than the corresponding entries under $\mathrm{S}_{\max }$. For FT very little selection pressure could be applied for high performance in combination with high sensitivity $(\mathrm{Hh})$ and the selection pressure for low sensitivity in combination with high performance ( $\mathbf{H l})$ was actually positive relative to that of the controls. For FH very little selection pressure could be applied for low performance in combination with high sensitivity $(\mathrm{Lh})$ or for low sensitivity in combination with high sensitivity (Lh) or for low sensitivity in combination with low performance $(\mathrm{Ll})$. These difficulties in finding particular combinations of performance and sensitivity among the $\mathrm{F}_{3}$ and $\mathrm{F}_{4}$ families are inevitably reflected in the cumulative responses listed in the $\mathrm{R}$ column of table 3.

From the qualitative point of view one of the four selections for FT. namely, that for low performance combined with high sensitivity (Lh) was unsuccessful. This had only a marginally lower performance and a lower sensitivity than the controls. Also for $\mathrm{FH}$ only the selection combining high performance and low sensitivity ( $\mathrm{Hl}$ ) was unsuccessful. While its sensitivity was relatively low it was higher than that of the controls. Viewed quantitativcly, however, the responses of all eight selections reflected the often low magnitudes of the selection pressures (S) that the parental populations permitted us to impose.

We can quantify the overall outcome of our selections by a simple orthogonal set of comparisons among the orthogonal set of selections. For each character we can partition the three degrees of freedom for differences among the four selections into the following three comparisons.

$$
\begin{array}{ll}
\text { H v L: } & \frac{1}{4}(\mathrm{Hh}+\mathrm{Hl}-\mathrm{Lh}-\mathrm{Ll}) \\
\mathrm{h} \text { v l: } & \frac{1}{4}(\mathrm{Hh}-\mathrm{Hl}+\mathrm{Lh}-\mathrm{Ll}) \\
\text { Interaction: } & \frac{1}{4}(\mathrm{Hh}-\mathrm{Hl}-\mathrm{Lh}+\mathrm{Ll})
\end{array}
$$

These three comparisons can be made using our measures of performance or our measures of sensitivity of the four selections and in respect of the selection pressures applied or the responses obtained. If we make these three comparisons on mean performance, $\mathrm{H} v \mathrm{~L}$ measures the mean difference in performance while $\mathrm{h} v \mathrm{l}$ and interaction measure the extent to which there are additive or non-additive differences in performance arising from the selected differences in sensitivity. The smaller these two items the greater the independence between performance and sensitivity over the four selections. 
Contrariwise, if we make the same three comparisons on our measure of sensitivity, h v 1 measures the mean difference in sensitivity while $\mathrm{H}$ v L and interaction measure the extent to which there are additive or nonadditive differences in sensitivity arising from the selected differences in performance. Again the smaller these two items are the greater is the independence of performance and sensitivity over the four selections.

We can, therefore, determine the extent of the interdependence of performance and sensitivity and we can do so both in terms of the selection imposed and the response observed. Because our primary aim has been to break down and reassort any association between performance and sensitivity, these comparisons provide us with an overall assessment of the extent of the progress made.

We can illustrate these points by reference to the $S_{\max }$ data in table 3 . By their nature these data should not show any cross influence between performance and sensitivity other than can be generated by sampling variance. And this is indeed what the three comparisons for performance and for sensitivity show. Almost all the differences in performance among the four selections for FT and FH are taken out by the single comparison H v L. Similarly, almost all the differences in sensitivity are taken out by the $\mathrm{h} \vee \mathrm{l}$ comparison. There is, therefore, as expected, very little interdependence between performance and sensitivity in these $S_{\max }$ data.

If we make the same comparisons for the $\mathrm{S}$ data in table 3 , the interdependence that we have already noted when we select for performance and sensitivity simultaneously clearly emerges. For FT the differences in performance and in sensitivity among the four selections are almost equally distributed among all three comparisons. There are, therefore, strong additive and non-additive influences of the selection for sensitivity on performance and of the selection for performance on sensitivity. For FH, on the other hand, by far the largest proportion of the differences in performance is attributable to the $\mathrm{H} \vee \mathrm{L}$ comparison and the largest proportion of the differences in sensitivity is attributable to the $h \mathrm{v} l$ comparison. In both cases, however, the other two comparisons are responsible for a greater proportion of these differences than in the $S_{\max }$ data. There is, therefore, greater interdependence between performance and sensitivity for $\mathrm{FH}$ than can be attributed solely to sampling variances.

The three comparisons for the $\mathrm{R}$ data in table 3 reflect, as would be expected, those for the $\mathrm{S}$ data. There is, for example, considerably more evidence of the influence of the selection for sensitivity on the response for performance for FT than for FH. For the response for sensitivity, however, both characters display an equally strong influence of the selection for performance. For each of the three components of the selection pressure (S) and the response to selection $(\mathrm{R})$ we can calculate a realised heritability as the ratio $\mathrm{R} / \mathrm{S}$. These are listed in table 3 . For both characters, the realised heritability for the direct response of performance to the selection for performance ( $\mathrm{H}$ v L for performance) is high and much higher than the realised heritability for the direct response of sensitivity to the selection for sensitivity ( $\mathrm{h} v \mathrm{l}$ for sensitivity). In general the indirect effects arising from the interdependence of performance and sensitivity have lower realised heritabilities although this is less marked for FT than for FH presumably because of the greater interdependence for FT.

$38 / 2-G$ 


\section{Conclustons}

Our aim has been to show that the widely encountered association between mean performance and environmental sensitivity can be broken following opportunities for recombination and segregation by producing selections which combine high and low performance with high and low sensitivity in all four possible combinations. To measure sensitivity in segregating material individual, segregating families must be replicated in two or more contrasting environments and hence the family must be the unit for selection. To select for any character, including those which can only be measured at the end of the growing season, sibs of the selected families must be subsequently raised to produce the progeny families of the selected parents. In spite of the restrictions these two requirements impose on the experimental design, the selection intensity and the number of cycles of selection that can be carried out per year, the selections succeeded to the extent that three of the four selections for FT and for FH qualitatively met the selection criteria. Nevertheless the selections displayed smaller differences in performance and in sensitivity than would have been achieved if performance and sensitivity had been selected for independently. There arc two apparent contributory causes. First, inspection of $S_{\max }$ and $S$ in table 3 shows that the selection pressure that could be imposed when selecting for sensitivity simultaneously with performance was on average about onethird to a quarter of that which could have been imposed if we had selected for sensitivity alone. There was clearly a shortage of segregants with the required levels of sensitivity in combination with the extremes of performance. Second, the heritability of performance realised during the selections was higher than for sensitivity (table 3 ). This is almost certainly attributable to the greater unreliability of the measure of sensitivity over seasons (see section 2).

These shortcomings can be partially overcome or avoided by assessing and selecting among random samples of inbred lines produced by single seed descent rather than using the procedures described in this paper. A comparison of the outcome of these two alternative procedures will be the subject of a further paper.

\section{RefERENGES}

FALCONER, D. S. 1960. Introduction to Quantitative Genetics. Oliver and Boyd, Edinburgh and London.

PERKINS, JEAN M., AND JINKS, J. L. 1968. Environmental and genotype-environmental components of variability. III. Multiplc lines and crosses. Heredity, 23, 339-356.

PERKINS, JEAN M., AND JINKS, J. L. 1971. Specificity of the interaction of genotypes with contrasting environments. Heredity, 26, 463-474.

PERKINS, JEAN M., AND JINKS, J. L. 1973. The assessment and specificity of environmental and genotype-environmental components of variability. Heredity, 30, 111-126. 